\title{
Hemophilia, Complications and Management: Series of 3 Cases with a Brief Review of Literature
}

Kamal Kant Sahu*, Subhash Chander Varma, Pankaj Malhotra, Gaurav Prakash, Alka Khadwal, T D Yadav, Jasmina Ahluwalia, Neelam Varma Department of Internal Medicine, Postgraduate Institute of Medical, Education and Research, Chandigarh, India

\section{Introduction}

Hemophilic pseudo tumors are rare, but well known complication of severe hemophilia, which most frequently develop at the femur, tibia, pelvic bones [1]. A pseudotumor may occur spontaneously or following multiple bleeding episodesinto closed space which can either be bone or soft tissue resulting in loculated collection with encapsulation. As swelling enlarges, increasing pressure may also lead to slow destruction of adjacent structures Massive pseudo tumors are very rare in cases of mild/moderate Hemophilia. Here we would like to share our experience with three cases of hemophilia who presented with varied complications with brief description regarding management issues and review of literature.

\section{Case Report 1}

A-38-year-old male diagnosed as congenital Hemophilia A since 1985 with history of multiple bleeding episodes and transfusions with factor VIII concentrates presented with complaints of left sided limping and lump sensation over left lumbar area for 10 months, initially of the size of coconut that gradually enlarged to present massive size (Figures 1A and 1B) despite receiving multiple factor VIII concentrates. Examination and MRI abdomen (Figures $1 \mathrm{C}$ and $1 \mathrm{D}$ ) suggested massive pseudotumor in entire left lumbar region predominantly involving the lateral and posterior aspect and extending from posterior costal margin above to till iliac crest inferiorly. Coagulation profile revealed a PTT of 58 seconds. Factor VIII activity was $7.5 \%$ with absent VIII inhibitors and HCV positivity. With a goal to raise factor VIII activity to $80 \%$ he was transfused accordingly with Factor VIII concentrates and excision of pseudotumor was done without intra/postoperative complications.

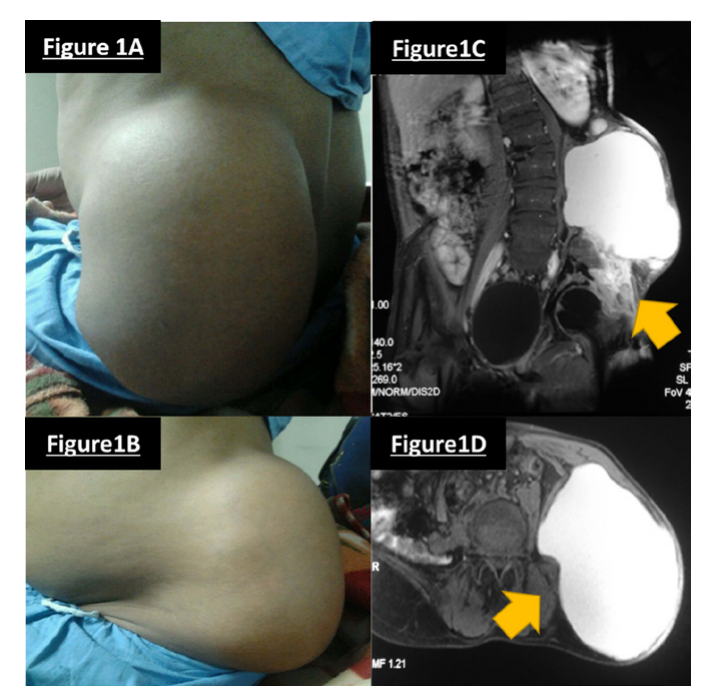

Figure 1: A. Back view of massive pseudotumor of approximately size of football involving left lumbar, iliac region. B. Front view of massive pseudotumor with few engorged vessels in overlying skin. C. T1 weighted coronal view (MRI abdomen) showing hyper intense soft tissue mass involving lumbar and iliac region with extension into unilateral femoral head cavity. D. T1 weighted axial view (MRI abdomen) at the level of lumbar region showing hyper intense soft tissue mass.
Intra-operatively on opening the abdomen it was found that the large parietal wall hematoma was well encapsulated and plane of excision could be easily delineated from surrounding structures like spleen, kidney and bowel lumen. However inferiorly plane could not be well demarcated and hence residual wall was left in pelvic cavity. Tumour excised was $15 \times 10 \times 8 \mathrm{~cm}$ in dimension with approximate weight of 2.5 $\mathrm{kg}$. Although pseudotumor was extending close to unilateral femoral cavity, however the head of femur was intact as evident from baseline MRI of hip joint, hence keeping this fact in mind hip replacement was not considered during the operation and plan was to keep patient in close follow up and consider repeat MRI hip joint after 6 months to reassess the skeletal framework along with soft tissue and decide accordingly (Table 1).

During postoperative period, average plasma factor activity of $80 \%$ was kept for $1^{\text {st }} 3$ days and thereafter reduced to average level of $65 \%$ for remaining hospitalized days. There was significant family history of similar bleeding tendencies in maternal grandfather and nephew. VIII level of his daughter and son were $75 \%$ and $94 \%$ respectively. He was discharged with advice to undergo hip replacement.

\section{Case Report 2}

A-19-year-old male being symptomatic since the age of 2 years for recurrent episodes of epistaxis and bleeding into major joints predominantly of knee and elbow and being diagnosed as Hemophilia $\mathrm{B}$ with history of multiple transfusions of fresh-frozen-plasma and factor IX concentrates in past. He now came for complaints of gradually increasing distension of right sided abdomen (Figures $2 \mathrm{~A}$ and $2 \mathrm{~B}$ ). Lab investigations revealed a PTT prolongation of 30 seconds, normal liver and renal function tests. His viral markers were negative, factor IX levels less than $1 \%$ (severe hemophilia B) with no inhibitor antibodies detected and CECT abdomen (Figures $2 \mathrm{~A}$ and $2 \mathrm{~B}$ ) showed large hyper dense lesion of approximately $20 \times 20$ centimeters occupying the right hypochondriac, paraumblical and lumbar region suggestive of

\begin{tabular}{|l|l|l|l|l|}
\hline Postoperativeday & $\begin{array}{l}\text { Factor VIII } \\
\text { dosage }\end{array}$ & $\begin{array}{l}\text { Factor VIII } \\
\text { level } \\
\text { (Trough level) }\end{array}$ & $\begin{array}{l}\text { Factor VIII } \\
\text { level } \\
\text { (Peak level) }\end{array}$ & $\begin{array}{l}\text { Bleeding } \\
\text { episodes }\end{array}$ \\
\hline DAY1-3 & $40 \mathrm{IU} / \mathrm{kg} \mathrm{BD}$ & $60 \%$ & $102 \%$ & No \\
\hline DAY4-6 & $25 \mathrm{IU} / \mathrm{kg} \mathrm{BD}$ & $60 \%$ & $101 \%$ & No \\
\hline DAY6 onwards & $15 \mathrm{IU} / \mathrm{kg}$ BD & $40 \%$ & $58 \%$ & No \\
\hline
\end{tabular}

Table 1: Postoperative day, dose given and therapeutic level (trough and peak level) of factor VIII.

*Corresponding author: Kamal Kant Sahu, Department of Internal Medicine, Postgraduate Institute of Medical, Education and Research, Chandigarh, India, E-mail: everlastingkamal@yahoo.com

Received November 19, 2013; Accepted December 26, 2013; Published December 28, 2013

Citation: Sahu KK, Varma SC, Malhotra P, Prakash G, Khadwal A, et al. (2013) Hemophilia, Complications and Management: Series of 3 Cases with a Brief Review of Literature. J Clin Case Rep 4: 325. doi:10.4172/2165-7920.1000325

Copyright: @ 2013 Sahu KK, et al. This is an open-access article distributed under the terms of the Creative Commons Attribution License, which permits unrestricted use, distribution, and reproduction in any medium, provided the original author and source are credited. 


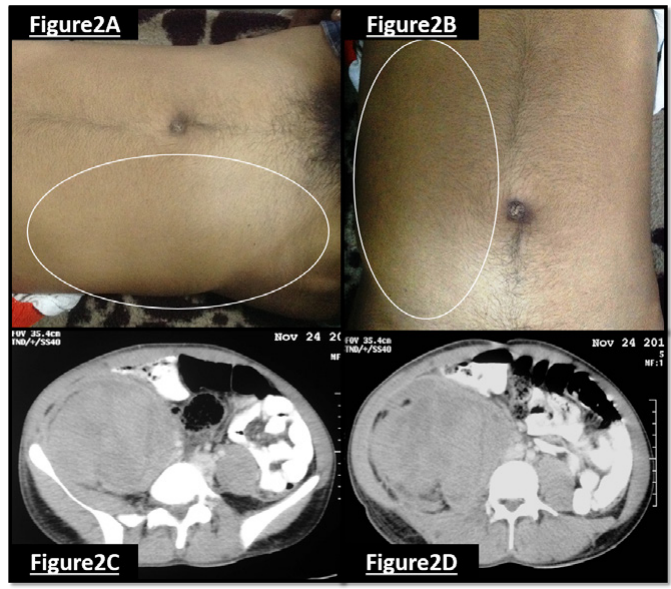

Figure 2: $\mathrm{A}$ and $\mathrm{B}$ : Clinical photograph of abdomen with bulge noted predominantly in right hypochondriac, paraumblical and lumbar region. $\mathrm{C}$ and D: CECT abdomen showing hyper dense lesion of approximately $20 \times 20$.
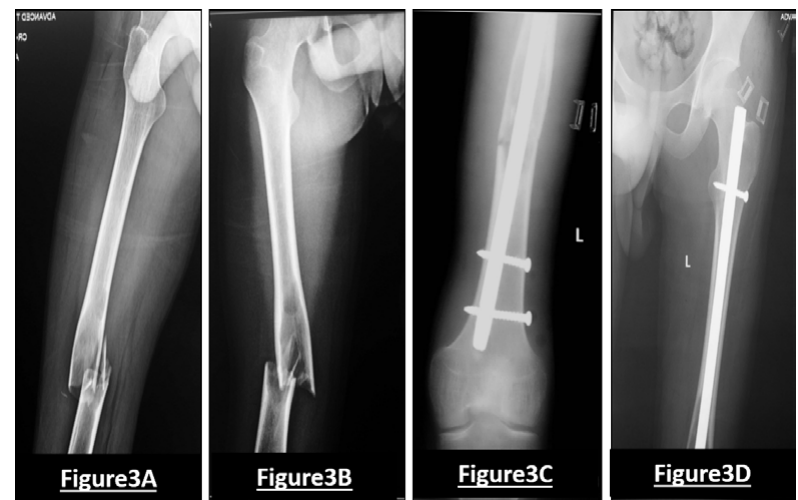

Figure 3: A and B: X-Ray anteroposteriorand lateral view of left thigh showing fracture shaft of femur respectively. $C$ and $D$ : X-Ray anteroposterior and lateral view of left thigh showingfixation of pathological shaft fracture by closed interlock nailing with $38 \times 11 \mathrm{~cm}$ nail respectively.

pseudotumor, successful excision of the same was done. We maintained $100 \%$ factor IX level during 1st three days by transfusing 5000 IU daily and later on with gradual tapering doses of factor IX concentrates of $3000 \mathrm{IU}$ and $2000 \mathrm{IU}$, serum factor IX levels of $60 \%$ and $40 \%$ was maintained over next 1-2 weeks. No postoperative complications were noted.

\section{Case Report 3}

This 17-year-old male, diagnosed case of hemophilia B presented to orthopedic OPD with complaints of fall and subsequently pain over left thigh. He underwent X-ray (Figures $3 \mathrm{~A}$ and $3 \mathrm{~B}$ ) and MRI of left thigh which showed fracture of left sided shaft of femur without hematoma formation. Baseline factor IX level were $<1 \%$ with no detection of inhibitors. Hence he underwentfixation of pathological shaft fracture by closed interlock nailing with $38 \times 11 \mathrm{~cm}$ nail (Figures $3 \mathrm{C}$ and $3 \mathrm{D}$ ). Similar to above case, this patient also was given factor IX concentrates with similar factor IX levels being maintained thorough out the course of his hospital without intra or post-operative complications.

\section{Discussion}

Hemophilia is challenging in many ways. Hemophilia B symptoms are similar to those of hemophilia A, including numerous, large deep bruises and prolonged bleeding. Lifelong risk of bleeding, hematoma formation, joint contracture, risk of blood transfusion infections like HCV, HBV, HIV, financial issues, social and psychological brunt's are few among the challenges which hemophilic patients go through on daily basis throughout their life, especially in resource constraint settings. The degree of severity of clinical manifestations depends on factor level. The joints are the most frequent site of bleeding followed by the soft tissues and bones [2].

Pseudo tumors or blood cysts are rare but dangerous complications of hemophilia, occurring in 1-2\% of patients with severe forms of the disease [2]. It is essentially a chronic, slowly expanding hematoma resulting from repetitive bleeding and is surrounded by thick fibrous capsule and most commonly develops in the femur, tibia and pelvic bones, while orbit, small bones of the hand, mandible, clavicle, spinal canal are less common site. The first description of hemophilic Pseudotumor was done by Starker in 1918 in a 14-year-old-male child. Clinically bleeding symptoms criteria may confuse because patients with factor VIII or factor IX levels $<1 \%$ occasionally have little or no spontaneous bleeding and appear to have clinically moderate or mild hemophilia. Further, the reverse is also true for patients with pro-coagulant activities of $1-5 \%$, who may present with symptoms of clinically severe disease [3] (Table 2).

\section{Treatment}

Even though treatment of hemophilia has undergone rapid development in the past decade, at present hemophilic pseudotumor lacks standard management guidelines. Decisions based on individual cases are more appropriate rather than fixed guidelines and treatment options range from varied approaches with factors replacement, arterial embolization, localized radiation and surgical excision:

\section{Conservative management}

Simplest of all, but most challenging among the available is conservative approach which requires clotting factor replacement to keep an activity of $80 \%-100 \%$ during intra-operative period at least. For patient with inhibitors, recombinant factor VIIa or prothrombin complex concentrates can be used. However in general, operative removal of the entire mass is a reliable treatment because the pseudotumor likely will reform if it is not completely removed.

\section{Surgical excision}

Surgical excision of entire mass is a reliable method as it ensures complete removal if done properly and prevents the risk of recurrence. Surgical intervention in the person with hemophilia may be elective or emergency in nature. Whenever possible, the patient should be transferred to a Hemophilia Treatment Centre. Recommendations suggest to maintain trough levels of either VIII and IX factors in between $80-100 \%$ for major surgeries during 1st three days and 60 $80 \%$ for next four days and latter of approximately $40-60 \%$ to sustain hemostatic status.

\section{Arterial embolization}

$1^{\text {st }}$ successful Trans catheter arterial embolization in a case of hemophilic pseudotumor was done by Pisco in 1990 [17]. After this, many case reports have been published till now sharing the experience of embolization of feeding vessels to pseudotumor [17-20]. Ethanol is a well-known sclerosing agent with curative potential. It exerts a direct toxic effect on the vascular wall, inducing significant thrombosis by denaturing blood proteins, dehydrating vascular endothelial cells, and 


\begin{tabular}{|c|c|c|c|}
\hline Author (year of publication) & Hemophilia type & Location of pseudotumor & Therapy \\
\hline Present case 1 (2013) & Hemophilia A & Intra-abdominal parietal mass & $\begin{array}{l}\text { Factor VIII replacement (ineffective) } \\
\text { Surgical excision }\end{array}$ \\
\hline Present case 2 (2013) & Hemophilia B & Intra-abdominal parietal mass & $\begin{array}{l}\text { Factor IX replacement } \\
\text { Surgical excision }\end{array}$ \\
\hline Present case 3 (2013) & Hemophilia B & Shaft fracture femur (left) & $\begin{array}{l}\text { Factor IX replacement andintramedullary closed interlock } \\
\text { nailing }\end{array}$ \\
\hline Purkait et al. (2013) [4] & Hemophilia B & Nasal Bone & Factor IX replacement (ineffective) Radiotherapy \\
\hline Kashiwazaki et al.(2012) [5] & Hemophilia A & Temporal Bone & Excision \\
\hline Serban et al. (2012) [6] & Hemophilia A & $\begin{array}{l}\text { Fistula betweeniliopsoas } \mathrm{h} \\
\text { ematoma \&bowel }\end{array}$ & Diversion colostomy \\
\hline Goel et al. (2012) [7] & Hemophilia B & Pleural based mass & Excision \\
\hline Pruzansky et al. (2012) [8] & Hemophilia A & Distal radius & Excision \\
\hline Throndson et al. (2011) [9] & Hemophilia A & Mandible & Curettage of lesion \\
\hline Mittal et al. (2011) [10] & Hemophilia B & Proximal tibia & Excision \\
\hline Ying et al. (2012) [11] & Acquired Hemophilia A & Pelvis & $\begin{array}{l}\text { Novo seven } \\
\text { Trans aortic embolization } \\
\text { Intralesional excision }\end{array}$ \\
\hline Cox et al. (2011) [12] & Hemophilia B & Mandible & Excision \\
\hline Rijal et al. (2010) [13] & Hemophilia A & Elbow joint & $\begin{array}{l}\text { Factor VIII replacement (ineffective) } \\
\text { Radiotherapy }\end{array}$ \\
\hline Liu et al. (2011) [14] & Hemophilia A and HIV & Right Hip joint & Hip joint amputation \\
\hline Kumar et al. (2011) [15] & & $\begin{array}{l}\text { Pelvic pseudotumor and pseudo } \\
\text { aneurysm }\end{array}$ & $\begin{array}{l}\text { Factor IX replacement (ineffective) Coil embolization } \\
\text { followed by surgical extirpation of the lesion } 24 \text { hours } \\
\text { later. }\end{array}$ \\
\hline Garcia-Perez et al. (2010) [16] & Hemophilia A & Intraabdominal pseudotumor & Factor VIII replacement Surgical excision \\
\hline
\end{tabular}

Table 2: Few recent publications of pseudotumor involving various regions and therapy.

precipitating the protoplasm, denuding the vascular wall of endothelial cells [21]. However some studies have indicated that embolization alone is not sufficient to eliminate blood supply to the pseudotumor in the long-term, and collateral circulation may soon develop from adjacent tissues, resulting in recurrent bleeding [22].

\section{Role of radiotherapy}

Radiotherapy has come up with convincing data in terms of promising modality of treatment in cases where surgery is contraindicated, or resistant to conservative treatment. Kang et al. in 1999 reported successful treatment of hemophilic pseudotumor located in ulna with low dose radiation (total dose of $900 \mathrm{cGy}$ in 6 fractions) [23]. Purkait et al. [4] reported a case of Hemophilia A with nasal bone pseudotumor with complaints of recurrent epistaxis which was refractory to conventional factor IX deficiency. Similar case report by Rijal et al. [13] have supported the role of radiotherapy in pseudo tumors. Similarly Ozbek et al. treated a 13-year-old hemophilic boy who had a pseudotumor of the tibia with low-dose radiotherapy (600 cGy) successfully [24]. The exact mechanism of hemophilic pseudotumor to respond to radiotherapy is not known. However different opinion suggests that radiation results in:

(a) Endarteritis in an acute bleeding hematoma [25]

(b) Direct injury of small vessels causing fibrosis and healing [26]

(c) Stimulation of fibroblasts resulting in fibrosis [23].

There has been considerable variation in the literature in radiotherapy dose. As low as $600 \mathrm{cGy}$ to as high as $2350 \mathrm{cGy}$, with or without factor replacement, have shown good response with complete resolution of lesions. However most of the data available in literature regarding use of radiotherapy primarily in the treatment of pseudo tumors were those in which the hematomas are located intraosseously or within close compartment like orbit and in cases were patients had presence of anti-hemophilic factor antibodies. And hence in all these such above mentioned conditions, it will be risky to operate upon surgically and better to opt localized radiotherapy, however in our 1st two cases we did not primarily considered radiotherapy due to massive size of pseudotumor with lack of convincing data for role of radiotherapy in such bulky hematomas and absence of inhibitors making surgical excision safe and one time procedure without risk of any unwanted radiation exposure. Even though, no standard radiation dose and fractionation schedule exists in the management of hemophilic pseudo tumors, radiation therapy should be tried in cases especially where lesions are located in the bone with growth potential and with presence of anti-hemophilic factor antibodies and with significant surgical risks [23].

\section{Conclusion}

Above mentioned series of three cases suggest that hemophiliac individuals are at potential risk of recurrent internal bleed leading to massive pseudo tumors which are although rare in mild/moderate hemophilia A but can occur to such severity so as to cause extensive bone destruction and adequate replacement therapy in the perioperative period is necessary to achieve safe surgical removal. Similarly orthopedic procedures which seem to be simple in normal individuals but may be challenging and complicated in case of hemophiliacs and needs excellency in surgical skills and adequate support in terms of availability of factor concentrates to ensure hemostasis during intra as well as post-operative period.

\section{Acknowledgement}

Dr. Kamal Kant Sahu-Wrote the paper; Dr. Gaurav Prakash-Assisted in manuscript and discussion; Dr. AlkaKhadwal-Assisted in manuscript and discussion Dr. Pankaj Malhotra-Designed the work; Dr. Subhash Chander Varma-Designed the work; Dr. T.D Yadav- Performed the surgery of intra-abdominal pseudo tumors: Dr. Sandeep Patel-Performed closed interlock nailing for fixing fracture of shaft of femur; Dr. JasminaAhluwalia- Performed mixing studies to assess factor VIII and IX levels and detection of inhibitors; Dr. NeelamVarma- Performed mixing studies to assess factor VIII and IX levels and detection of inhibitors. 
Citation: Sahu KK, Varma SC, Malhotra P, Prakash G, Khadwal A, et al. (2013) Hemophilia, Complications and Management: Series of 3 Cases with a Brief Review of Literature. J Clin Case Rep 4: 325. doi:10.4172/2165-7920.1000325

\section{References}

1. Lima GS, Robaina TF, de Queiroz Chaves Lourenço S, Dias EP (2008) Maxillary hemophilic pseudotumor in a patient with mild hemophilia A. J Pediatr Hematol Oncol 30: 605-607.

2. Kilic YA, Dundar SV, Onat D, Akhan O (2009) lliopsoas hemophilic pseudotumor with bowel fistulization. Bratisl Lek Listy 110: 729-731.

3. Mishra KL, Kumar A, Gupta A (2008) An experience of single centre at C S M Medical University, Lucknow, for the prevalence of hemophilia in Uttar Pradesh. Indian J Hematol Blood Transfus. 24: 49-53.

4. Purkait R, Mukherjee A, Naskar S, Bhadra R (2013) Nasal hemophilic pseudotumor: favorable response to radiotherapy. Indian Pediatr 50: 334-335.

5. Kashiwazaki D, Terasaka S, Kamoshima Y, Kubota K, Asano T, et al. (2012) Hemophilic pseudotumor of the temporal bone with conductive hearing loss-case report. Neurol Med Chir (Tokyo) 52: 745-747.

6. Serban M, Mihailov D, Savescu D, Bordos D, Talpos Niculescu S, et al (2012) Long-term outcome of an unusual haemophilic pseudotumour. Hamostaseologie 32 Suppl 1: S43-44.

7. Goel MK, Juneja D, Jain SK, Chaudhuri SK, Kumar A (2012) An unusual case of pleural-based tumor with life-threatening post-operative complication. Indian J Crit Care Med 16: 48-51.

8. Pruzansky JS, Gilbert MS, Garcia RA, Gilbert RS (2012) Intraosseous pseudotumor of the distal radius in a patient with hemophilia: case report. J Hand Surg Am 37: 532-537.

9. Throndson RR, Baker D, Kennedy P, McDaniel K (2011) Pseudotumor of hemophilia in the mandible of a patient with hemophilia A. Oral Surg Oral Med Oral Pathol Oral Radiol Endod.

10. Mittal S, Arora S, Khanna S, Maini L, Gautam VK (2011)An unusual presentation of hemophilia B: pseudotumor of proximal tibia. Am J Orthop (Belle Mead NJ) 40: E138-140.

11. Ying SH, Chen WM, Wu PK, Chen CF, Liu CL, et al. (2012) Pelvic hemophilic pseudotumor presenting as severe sciatic pain in a patient with no history of hemophilic symptoms. J Orthop Sci 17: 490-494.

12. Cox DP, Solar A, Huang J, Chigurupati R (2011) Pseudotumor of the mandible as first presentation of hemophilia in a 2-year-old male: a case report and review of jaw pseudotumors of hemophilia. Head Neck Pathol 5: 226-232.

13. Rijal L, Neogi DS, Ansari MT, Khan SA, Yadav CS (2010) Hemophilic pseudotumor--is there a role of radiotherapy? Literature review and a case report. Nepal Med Coll J 12: 193-197.
14. Liu B, Liu L, Feng Y, Li L (2011) A case report on the surgical treatment of the huge inflammatory pseudotumor in the AIDS patient with hemophilic. Case Rep Pathol 2011: 798649

15. Kumar R, Pruthi RK, Kobrinsky N, Shaughnessy WJ, McKusick MA, et al (2011) Rodriguez V. Pelvic pseudotumor and pseudoaneurysm in a pediatric patient with moderate hemophilia B: successful management with arterial embolization and surgical excision. Pediatr Blood Cancer. 56: 484-487.

16. Garcia-Perez R, Torres-Salmeron G, Sanchez-Bueno F, Garcia-Lopez A Parrilla-Paricio P (2010) Intraabdominal hemophilic pseudotumor: case report Rev Esp Enferm Dig 102: 275-280.

17. Pisco JM, Garcia VL, Martins JM, Mascarenhas AM (1990) Hemophilic pseudotumor treated with transcatheter arterial embolization: case report. Angiology 41: 1070-1074.

18. Fan XD, Su LX, Zheng JW, Zheng LZ, Zhang ZY (2009) Ethanol embolization of arteriovenous malformations of the mandible. AJNR Am J Neuroradiol 30: 1178-1183.

19. Sevilla J, Alvarez MT, Hernández D, Canales M, De Bustos JG, et al. (1999) Therapeutic embolization and surgical excision of haemophilic pseudotumour Haemophilia 5: 360-363.

20. Klamroth R, Gottstein S, Essers E, Landgraf H, Wilaschek M,et al. (2009) Oldenburg J. Successful angiographic embolization of recurrent elbow and knee joint bleeds in seven patients with severe haemophilia. Haemophilia 15 247-252.

21. Yakes WF, Haas DK, Parker SH, Gibson MD, Hopper KD, et al. (1989) Symptomatic vascular malformations: ethanol embolotherapy. Radiology 170 : 1059-1066.

22. Espandar R, Heidari P, Rodriguez-Merchan EC (2009) Management of haemophilic pseudotumours with special emphasis on radiotherapy and arterial embolization. Haemophilia 15: 448-457.

23. Kang JO, Cho YJ, Yoo MC, Hong SE (2000) Hemophilic pseudotumor of the ulna treated with low dose radiation therapy: a case report. J Korean Med Sci 15: 601-603.

24. Ozbek N, Unsal M, Kara A, Gumruk F, Gurgey A (1996) Treatment of hemophilic pseudotumor with low-dose radiotherapy. Turk J Pediatr 38: 91-94.

25. Brant EE, Jordan HH (1972) Radiologic aspects of hemophilic pseudotumors in bone. Am J Roentgenol Radium Ther Nucl Med 115: 525-539.

26. Reinhold HS (1974) The influence of radiation on blood vessels and circulation Chapter IV. Structural changes in blood vessels. Curr Top Radiat Res Q 10: 58-74. 